\title{
Crizotinib in anaplastic lymphoma kinase- positive anaplastic large cell lymphoma in the setting of renal insufficiency: a case report
}

\author{
Shalin Kothari ${ }^{*}$, Najam Ud-Din ${ }^{2}$, Michele Lisi ${ }^{3}$ and Thomas Coyle ${ }^{2}$
}

\begin{abstract}
Background: In vitro studies confirmed cytoreductive anti-tumor activity of crizotinib in experimental models of anaplastic large cell lymphoma in 2007. One case series and a few case reports describe the use of crizotinib in relapsed or refractory anaplastic lymphoma kinase-positive anaplastic large cell lymphoma. Even though data are limited regarding the dose of crizotinib in renal insufficiency, our case was successfully treated with a lower dose of crizotinib.

Case presentation: We report the case of a 48-year-old white man who had progressive disease after three prior cycles of cyclophosphamide, doxorubicin, vincristine and prednisone and three cycles of ifosfamide, carboplatin, and etoposide, and was not a candidate for high-dose chemotherapy and transplant due to poor performance status and renal insufficiency; he had a complete and durable response to single agent crizotinib. Crizotinib was given at a reduced dose (250 mg once daily) due to his renal insufficiency. He has been in complete remission for more than 2 years.

Conclusions: Our experience confirms the activity of crizotinib in this disease; it suggests that long-term treatment with crizotinib is a reasonable option in patients who are not candidates for more aggressive therapy and indicates that crizotinib can be used successfully at reduced doses in patients with pre-existing renal insufficiency. The role and timing of crizotinib in anaplastic lymphoma kinase-positive anaplastic large cell lymphoma is unclear, but the current literature that we review here provides promising results that may lead to studies of crizotinib earlier in the course of disease.
\end{abstract}

Keywords: ALK, Anaplastic large cell lymphoma, Crizotinib, Renal insufficiency

\section{Background}

Systemic anaplastic large cell lymphoma (ALCL) is a rare subtype of peripheral $\mathrm{T}$ cell lymphoma representing approximately $3 \%$ of non-Hodgkin's lymphoma (NHL), often presenting with advanced disease, B symptoms and extranodal disease [1]. Anaplastic lymphoma kinasepositive $(\mathrm{ALK}+)$ ALCL is characterized by a specific chromosomal translocation, $\mathrm{t}(2 ; 5)(\mathrm{p} 23 ; 35)$ which fuses the $A L K$ gene on chromosome 2 with the nucleophosmin

\footnotetext{
*Correspondence: kotharis@upstate.edu

'Department of Medicine, SUNY Upstate Medical University, 750 E Adams St., Syracuse, NY 13210, USA

Full list of author information is available at the end of the article
}

$(N P M)$ gene on chromosome 5, resulting in a NPM-ALK fusion protein, ALK overexpression and constitutive tyrosine kinase activity [2]. Other partner genes for $A L K$ translocation events have been described, including TPM3, TFG, MSN, CLTC, and ATIC. However, NPMALK accounts for more than $75 \%$ of the ALK+ ALCL cases reported $[3,4]$. ALK+ ALCL generally have a good response to standard chemotherapy and relatively good prognosis, with approximately $60 \%$ of patients remaining in remission 5 years after frontline therapy [5]. However, the prognosis of patients with refractory or relapsed disease is poor [6]. Furthermore, the small cell variant of ALK+ ALCL has a worse prognosis [7]. 
Approaches to treatment of relapsed or refractory disease have included high-dose chemotherapy and autologous stem cell transplant (auto-SCT), allogeneic stem cell transplant (allo-SCT), and a number of second-line chemotherapy agents including brentuximab vedotin [8]. Recently, several case reports and small series have shown impressive responses of relapsed/refractory ALK+ ALCL to crizotinib, a specific inhibitor of the ALK kinase. We now report further a case of a patient with refractory ALK+ ALCL with a complete durable response to single agent crizotinib. This patient has been in (CR) for more than 2 years, on a reduced dose of crizotinib due to pre-existing renal failure.

\section{Case presentation}

Our patient was a 48-year-old white man with past medical history of diabetes mellitus type 2 who was diagnosed with stage IV ALK+ ALCL, small cell variant, after presenting with $\mathrm{B}$ symptoms, right axillary and supraclavicular lymphadenopathy and splenomegaly. ALK positivity was confirmed using immunohistochemistry and fluorescent in situ hybridization employing an ALK break-apart probe. He received three cycles of cyclophosphamide, doxorubicin, vincristine, and prednisolone (CHOP) but had progression of disease with a necrotic spleen, continued $\mathrm{B}$ symptoms, and a malignant left pleural effusion. He was subsequently treated with splenectomy and drainage of the pleural effusion with a PleurX catheter, and his chemotherapy was changed to ifosfamide, carboplatin, and etoposide (ICE) in an attempt to prepare for an auto-SCT. The pathology from his spleen showed persistent viable lymphoma. He received three cycles of ICE chemotherapy. He initially partially responded to it, but the therapy was complicated by episodes of encephalopathy due to ifosfamide and the development of progressive renal insufficiency. His baseline serum creatinine was $0.8 \mathrm{mg} / \mathrm{dl}$, but it rose to $1.8 \mathrm{mg} / \mathrm{dl}$ by the time of the third cycle of ICE and subsequently peaked at a level of 5 to $6 \mathrm{mg} / \mathrm{dl} 2$ months later. A renal biopsy showed lymphocytic interstitial nephritis.

Crizotinib, at a dose of $250 \mathrm{mg}$ twice a day, was added to the regimen immediately following the second cycle of ICE, but it was discontinued after 7 days due to diarrhea. Six weeks after receiving his third cycle of ICE, he again developed fevers (temperatures $>39^{\circ} \mathrm{C}$ ), axillary adenopathy, and a decline in Eastern Cooperative Group (ECOG) performance status from 1 to 3 . Persistent disease was demonstrated by ${ }^{18} \mathrm{~F}$-fluorodeoxyglucose (FDG) avidity on positron emission tomographic (PET) and computed tomographic (CT) images of his retroperitoneal and right axillary lymph nodes. We thought that he was no longer a candidate for auto-SCT or allo-SCT due to a poor performance status, resistant disease, and renal failure.
Crizotinib was restarted at a dose of $250 \mathrm{mg}$ once a day (Day 0). His fevers disappeared within 24 hours. Other B symptoms and palpable axillary adenopathy resolved in a week. PET and CT images performed at Day 76 showed complete resolution of previously FDG-avid lesions (Fig. 1). His CR has persisted for 29 months on continued therapy with $250 \mathrm{mg}$ of crizotinib orally once daily. Adverse effects including transient thrombocytopenia and diarrhea have been mild. His renal disease has stabilized with creatinine levels between $4 \mathrm{mg} / \mathrm{dl}$ and $5 \mathrm{mg} / \mathrm{dl}$ without specific treatment and without the need for dialysis.

Crizotinib is a well-tolerated small molecule inhibitor of the ALK tyrosine kinase. It has significant activity in nonsmall cell lung cancers (NSCLCs) bearing an activating EML4-ALK translocation and is approved by the US Food and Drug Administration (FDA) for this indication. Crizotinib has been shown to have in vitro activity against ALK-positive lymphomas [9]. Crizotinib induces apoptosis due to down-regulation of PSTAT3 and BCL-2 family proteins [10] and has excellent potential to treat patients with refractory ALK-positive ALCL, such as our case.

Several case reports and small series have appeared on the use of crizotinib in adult patients with relapsed/refractory ALK+ ALCL which indicate that such lymphomas have a high chance of responding to crizotinib, even when heavily pretreated, with approximately half enjoying long-lasting responses; however, no pretreatment parameter is able to predict a durable CR [11-14]. These cases are summarized in Table 1. A high percentage of patients, but not all, respond to treatment with prompt resolution of B symptoms and rapid complete

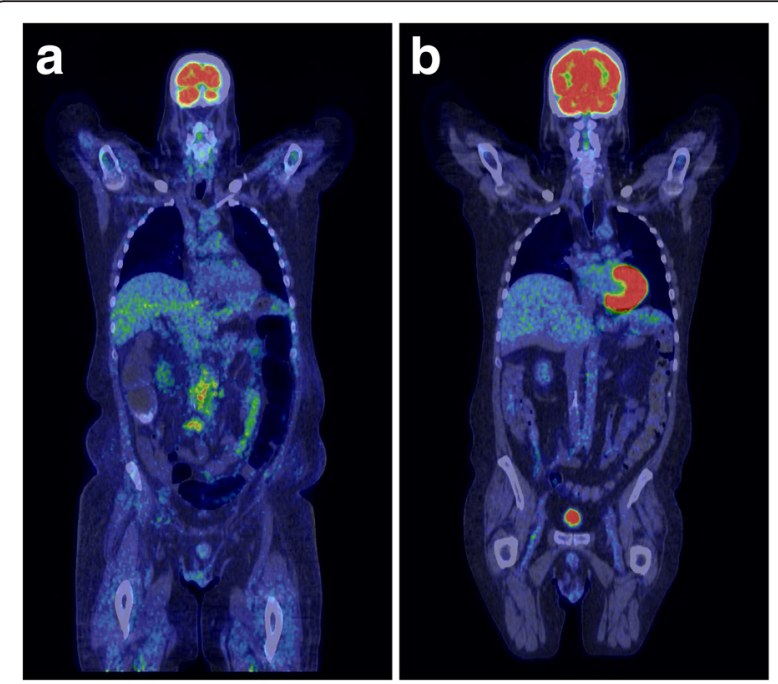

Fig. 1 a ${ }^{18}$ F-fluorodeoxyglucose positron emission tomography/ computed tomography on Day 0 shows significant retroperitoneal lymphadenopathy. b ${ }^{18} \mathrm{~F}$-fluorodeoxyglucose positron emission tomography/computed tomography on Day 76 shows complete resolution of the retroperitoneal lymphadenopathy 
Table 1 Reported cases of the use of crizotinib in anaplastic lymphoma kinase-positive anaplastic large cell lymphoma

\begin{tabular}{|c|c|c|c|c|c|}
\hline Study & Age & $\begin{array}{l}\text { Stage } \\
\text { (Ann Arbor) }\end{array}$ & ECOG & Previous therapy lines & Response, in months \\
\hline \multirow[t]{9}{*}{ Gambacorti Passerini et al. 2014 [11] } & 26 & $\mathrm{IIIB}$ & 2 & CHOP, DHAP, HD-VP16 & $C R,>40$ \\
\hline & 19 & IVB & 3 & CHOP, DHAP, BEAM & $C R, 2$ \\
\hline & 22 & $\| B$ & 1 & CHOP, VAD, H-CyVAD & $C R,>35$ \\
\hline & 20 & $\| B$ & 2 & CHOP, DHAP, BEAM & $C R, 2$ \\
\hline & 47 & $\| \mathrm{IIB}$ & 2 & IEV, CHOP, DHAP & $C R_{1}>30$ \\
\hline & 28 & IIIBe & 2 & CHOP, DHAP, miniBEAM & $C R, 2$ \\
\hline & 34 & IVBe & 2 & CHOP, ESHAP & $C R, 3$ \\
\hline & 38 & IVB & 4 & CHOP, DHAP, VIM & $C R, 8$ \\
\hline & 55 & $\| \mathrm{IIB}$ & 1 & $\mathrm{CHOP}$ & $C R,>21$ \\
\hline Ordemann et al. 2013 [12] & 29 & na & na & CHOP-21, DHAP, Dexa-BEAM & $P R, 1$ \\
\hline Cleary et al. 2014 [13] & 34 & na & na & $\begin{array}{l}\text { CHOP, gemcitabine-based therapy, } \\
\text { pralatrexate, Mtx, brentuximab }\end{array}$ & CR, 30; allo-SCT at week 13 \\
\hline Conyers et al. 2014 [14] & 22 & $\| \mathrm{IIB}$ & na & $\mathrm{CHOP}$ & $\mathrm{CR},>21$; allo-SCT at 2 months \\
\hline Current case & 48 & IV & 3 & CHOP, ICE & $C R,>29$ \\
\hline
\end{tabular}

allo-SCT allogeneic stem cell transplant, BEAM carmustine, etoposide, cytarabine, melphalan, $C H O P$ cyclophosphamide, doxorubicin (adriamycin), vincristine, prednisone, $C R$ complete response, Dexa-BEAM dexamethasone, carmustine, etoposide, cytarabine, melphalan, $D H A P$ dexamethasone, cisplatin, cytarabine, ECOG Eastern Cooperative Group, ESHAP etoposide, methylprednisolone, cytarabine, cisplatin, H-CyVAD alternate regimens of 1) cyclophosphamide, vincristine, doxorubicin (adriamycin), dexamethasone; 2) methotrexate and cytarabine; HD-VP16 high-dose etoposide, ICE ifosfamide, carboplatin, etoposide, IEV Ifosfamide, epirubicin, etoposide, miniBEAM carmustine, etoposide, cytarabine, melphalan, Mtx methotrexate, na not available, $P R$ partial response, VAD vincristine, doxorubicin, high-dose dexamethasone, VIM ifosfamide, mitoxantrone, etoposide

radiographic responses as shown by PET-CT. The crizotinib dose generally used was $250 \mathrm{mg}$ twice a day. The treatment was well tolerated. In a number of the cases, crizotinib was used as a bridge to allo-SCT, although in one of those studies the patient relapsed in 4 weeks on crizotinib before the allo-SCT could be done [12]. Other patients have continued on treatment with single agent crizotinib with durable response. In the largest of these series, reported by Gambacorti Passerini et al., crizotinib was given to nine patients with refractory/relapsed ALK + ALCL and all of them responded initially. Four of these patients remained in $\mathrm{CR}$ on continuous crizotinib therapy at 21 to 40 months follow-up. Two had undergone allo-SCT and remain in CR, of which one was still on crizotinib. Two of the nine patients had subsequent progression of the disease [11]. A prospective phase I trial in pediatric patients with several malignancies was performed by the Children's Oncology Group. It showed that of nine patients with ALK-mutated NHL, eight responded and seven had CRs and five remained on crizotinib in long-term remission [15].

Our patient did not tolerate crizotinib given at full dose in combination with ICE chemotherapy. It is unclear if this was due to concomitant ICE chemotherapy or due to decreased clearance of the drug due to his renal insufficiency. Crizotinib was restarted at a reduced dose of $250 \mathrm{mg}$ daily as a single agent after recovery from the last cycle of ICE chemotherapy. He has tolerated this without problems and without further kidney injury or the need for dialysis. Renal pathology had showed acute interstitial nephritis, which was thought to be secondary to proton pump inhibitor (PPI) that was initiated around that time and the PPI was stopped immediately. At the time of initiation of reduced dose of crizotinib, no literature was available on the interaction of crizotinib with reduced renal function. In NSCLC trials, crizotinib at $250 \mathrm{mg}$ twice a day reaches steady state in 15 days and then dose levels decrease nonlinearly. There were no differences in pharmacokinetics (PK) levels for mild to moderate renal insufficiency. It would be a good study question to look at the PK levels for crizotinib in patients with renal impairment in conditions other than NSCLC. Recent literature recommends arbitrary dose adjustment (200 mg twice a day or 250 mg once daily) in the presence of renal insufficiency [16], but the exact dosing in this situation still remains unknown and further research is needed.

\section{Conclusions}

This experience suggests that single agent crizotinib is a viable option for patients with relapsed/refractory ALK+ ALCL who are not candidates for high-dose chemotherapy and auto-SCT or allo-SCT. Since crizotinib can yield long-term remissions in patients with relapsed/refractory $\mathrm{ALK}+\mathrm{ALCL}$, it is unclear if all patients with relapsed/refractory disease require high-dose chemotherapy and allo-SCT even if they are candidates for it. In addition, this experience demonstrated that crizotinib could be successfully employed at reduced doses in patients with renal insufficiency. 


\section{Acknowledgements}

We thank Dr Stephen Knohl for comments on the review of literature of crizotinib in renal disease and Dr Robert Hutchison for reviewing the pathology slides to confirm the diagnosis.

\section{Authors' contributions}

SK reviewed the chart of the patient, reviewed the current literature and drafted the manuscript. NU and TC provided scientific conclusions after analysis of the case report and reviewed literature, and edited the manuscript. ML provided radiology images and interpreted the radiographic data. All authors read and approved the final manuscript.

\section{Competing interests}

The authors declare that they have no competing interests.

\section{Consent for publication}

Written informed consent was obtained from the patient for publication of this case report and any accompanying images. A copy of the written consent is available for review by the Editor-in-Chief of this journal.

\section{Author details}

'Department of Medicine, SUNY Upstate Medical University, 750 E Adams St., Syracuse, NY 13210, USA. ${ }^{2}$ Division of Hematology/Oncology, Department of Medicine, SUNY Upstate Medical University, 750 E Adams St., Syracuse, NY 13210, USA. ${ }^{3}$ Department of Radiology, SUNY Upstate Medical University, 750 E Adams St., Syracuse, NY 13210, USA.

\section{Received: 27 May 2015 Accepted: 31 May 2016}

\section{Published online: 14 June 2016}

\section{References}

1. Stein H, Foss HD, Durkop H, Marafioti T, Delsol G, Pulford K, et al. CD3O(+) anaplastic large cell lymphoma: a review of its histopathologic, genetic, and clinical features. Blood. 2000;96(12):3681-95.

2. Morris SW, Kirstein MN, Valentine MB, Dittmer KG, Shapiro DN, Saltman DL, et al. Fusion of a kinase gene, ALK, to a nucleolar protein gene, NPM, in non-Hodgkin's lymphoma. Science. 1994;263(5151):1281-4.

3. Ferreri AJ, Govi S, Pileri SA, Savage KJ. Anaplastic large cell lymphoma. ALKpositive. Crit Rev Oncol Hematol. 2012;83(2):293-302. doi:10.1016/j. critrevonc.2012.02.005

4. Lowe EJ, Lim MS. Potential therapies for anaplastic lymphoma kinase-driven tumors in children: progress to date. Paediatr Drugs. 2013;15(3):163-9. doi:10.1007/540272-013-0027-3.

5. Savage KJ, Harris NL, Vose JM, Ullrich F, Jaffe ES, Connors JM, et al. ALKanaplastic large-cell lymphoma is clinically and immunophenotypically different from both ALK+ ALCL and peripheral T-cell lymphoma, not otherwise specified: report from the International Peripheral T-Cell Lymphoma Project. Blood. 2008;111(12):5496-504. doi:10.1182/blood-2008-01-134270.

6. Mak V, Hamm J, Chhanabhai M, Shenkier T, Klasa R, Sehn LH, et al. Survival of patients with peripheral T-cell lymphoma after first relapse or progression: spectrum of disease and rare long-term survivors. J Clin Oncol. 2013;31(16):1970-6. doi:10.1200/JCO.2012.44.7524.

7. Summers TA, Moncur JT. The small cell variant of anaplastic large cell lymphoma. Arch Pathol Lab Med. 2010;134(11):1706-10. doi:10.1043/2008-0624-RSR.1.

8. Foyil KV, Bartlett NL. Brentuximab vedotin and crizotinib in anaplastic large-cell lymphoma. Cancer J. 2012;18(5):450-6. doi:10.1097/PPO.0b013e31826aef4a.

9. Christensen JG, Zou HY, Arango ME, Li Q, Lee JH, McDonnell SR, et al. Cytoreductive antitumor activity of PF-2341066, a novel inhibitor of anaplastic lymphoma kinase and c-Met, in experimental models of anaplastic large-cell lymphoma. Mol Cancer Ther. 2007;6(12 Pt 1):3314-22. doi:10.1158/1535-7163.MCT-07-0365.

10. Hamedani FS, Cinar M, Mo Z, Cervania MA, Amin HM, Alkan S. Crizotinib (PF-2341066) induces apoptosis due to downregulation of PSTAT3 and BCL2 family proteins in NPM-ALK(+) anaplastic large cell lymphoma. Leuk Res. 2014;38(4):503-8. doi:10.1016/j.leukres.2013.12.027.

11. Gambacorti Passerini C, Farina F, Stasia A, Redaelli S, Ceccon M, Mologni L, et al. Crizotinib in advanced, chemoresistant anaplastic lymphoma kinasepositive lymphoma patients. J Natl Cancer Inst. 2014;106(2):djt378. doi:10.1093/jnci/djt378.

12. Ordemann R, Stohlmacher J, Beuthien-Baumann B, Platzek I, van den Hoff J, Kroschinsky F, et al. Use of targeted therapy for refractory ALK-positive anaplastic large cell lymphoma as a bridging strategy prior to allogeneic transplantation. Ann Hematol. 2013;92(1):125-7. doi:10.1007/s00277-012-1524-0.

13. Cleary JM, Rodig S, Barr PM, Shinagare AB, Clark JW, Shapiro GI, et al. Crizotinib as salvage and maintenance with allogeneic stem cell transplantation for refractory anaplastic large cell lymphoma. J Natl Compr Canc Netw. 2014;12(3):323-6. quiz 6.

14. Conyers R, Rao A, Solomon B, Seymour JF. Editor in Chief: Response to Eyre et al. ALK-positive anaplastic large cell lymphoma: current and future perspectives in adult and paediatric disease. Eur J Haematol. 2014. doi:10.1111/ejh.12404.

15. Mosse YP, Lim MS, Voss SD, Wilner K, Ruffner K, Laliberte J, et al. Safety and activity of crizotinib for paediatric patients with refractory solid tumours or anaplastic large-cell lymphoma: a Children's Oncology Group phase 1 consortium study. Lancet Oncol. 2013;14(6):472-80. doi:10.1016/S14702045(13)70095-0.

16. Martin Martorell P. Huerta Alvaro M, Solis Salguero MA, Insa MA. Crizotinib and renal insufficiency: a case report and review of the literature. Lung Cancer. 2014;84(3):310-3. doi:10.1016/j.lungcan.2014.03.001.

\section{Submit your next manuscript to BioMed Central and we will help you at every step:}

- We accept pre-submission inquiries

- Our selector tool helps you to find the most relevant journal

- We provide round the clock customer support

- Convenient online submission

- Thorough peer review

- Inclusion in PubMed and all major indexing services

- Maximum visibility for your research

Submit your manuscript at www.biomedcentral.com/submit
) Biomed Central 